\title{
Influência da adubação orgânica e densidade de plantio na produção do milho pipoca
}

\author{
Influence of organic manure and density planting in the \\ production of popcorn
}

Dácio Jerônimo de Almeida ${ }^{1 *}$, Ivandro França da Silva ${ }^{1}$, Remy Farias de Souza'. Flăvio Pereira da Mota Silveira ${ }^{1}$, Leonardo da Silva Santos ${ }^{1}$, Altamiro Oliveira de Malta'

\author{
Departamento de Solos e Engenharia \\ Rural, Centro de Ciências Agrărias, \\ Universidade Federal da Paraíba \\ (UFPB), campus II, Rodovia PB 079, \\ Km 12, CEP 58397-000, Areia, PB, \\ Brasil \\ *autor correspondente \\ \almeida_dacio@hotmail.com
}

RESUMO: O cultivo do milho pipoca (Zea mays everta) no Brasil aparece como uma opção para o produtor rural, apresentando maior rentabilidade econômica face ao melhor preço alcançado no mercado comparado com o do milho comum. O presente trabalho objetivou obter quantidade de adubo orgânico conciliada a um espaçamento que proporcione uma melhor produtividade de grãos de milho pipoca. A pesquisa foi conduzida na Estação Experimental da Empresa Estadual de Pesquisa Agropecuária da Paraíba (EMEPA-PB), no município de Alagoinha-PB, em um Luvissolo Crômico Pálico abrúptico. O delineamento experimental foi em blocos casualizados, com dimensões $60,00 \mathrm{~m} \times 5,00 \mathrm{~m}$, com parcelas de $5,00 \mathrm{~m} \times 5,00 \mathrm{~m}$, arranjados no esquema fatorial $2 \times 5$, com três repetições. Foram testados dois espaçamentos entre fileiras $(1,00 \mathrm{~m} \mathrm{e} 0,80 \mathrm{~m})$, com espaçamento entre plantas de $0,20 \mathrm{~m} \mathrm{e}$ cinco quantidades de adubo orgânico: $0,5,10$, 15,20 tha $^{-1}$ de esterco bovino. Utilizou a cultivar de milho CMS 42 da Embrapa. Foram avaliados: altura, diâmetro do colmo, produtividade e índice de capacidade de expansão dos grãos. Os dados obtidos foram submetidos à análise de variância, sendo a influência do fator Adubação testado pela regressão polinomial e a influência do fator Espaçamento pelo teste $\mathrm{F}$ a 5\%. A altura de plantas, os aumentos foram proporcionais ao aumento das quantidades de adubo orgânico aplicados, já o melhor diâmetro de colmo foi obtido com $5 \mathrm{t} \mathrm{ha}^{-1}$, a maior produtividade de grãos foi obtida com $18,31 \mathrm{t} \mathrm{ha}^{-1}$ no espaçamento $0,80 \times 0,20 \mathrm{~m}$.

PALAVRAS-CHAVE: Esterco bovino, espaçamento, Zea mays everta.
ABSTRACT: The cultivation of popcorn (Zea mays everta) in Brazil appears as an option for farmers, with higher economic profitability over the best price achieved in the market compared to the common corn. This study aimed to obtain quantity of organic fertilizer reconciled to a spacing that provides better productivity of popcorn kernels. The research was conducted at the Experimental State of the Station Company of Agricultural Research of Paraiba (EMEPA-PB), in the municipality of Alagoinha - PB, in a Luvisol Chromic Pálico abrúptico. The experimental design was randomized blocks with dimensions $60.00 \times 5.00 \mathrm{~m}$, with installments of $5.00 \mathrm{~m} \times 5.00 \mathrm{~m}$, arranged in a factorial $2 \times 5$, with three replications. Two row spacings were tested $(1.00 \mathrm{~m}$ and $0.80 \mathrm{~m})$, with plant spacing of $0.20 \mathrm{~m}$ five amounts of organic fertilizer: 0, 5, 10, 15, 20 tha - $^{-1}$ manure. Used to cultivate corn CMS 42 by Embrapa. They evaluated: height, stem diameter, productivity and grain expansion capacity index. The data were submitted to analysis of variance, and the influence of Fertilization factor tested by polynomial regression and the influence of Spacing factor by $F$ test at $5 \%$. The plant height, the increases were proportional to the increase in the quantities of organic fertilizer applied, since the best stem diameter was obtained with 5 t ha $\mathrm{a}^{-1}$, the highest grain yield was obtained with $18.31 \mathrm{tha}^{-1}$ in the spacing $0.80 \times 0.20 \mathrm{~m}$.

KEYWORDS: Cattle manure, spacing, Zea mays everta. 


\section{Introdução}

No Brasil, o milho pipoca é cultivado em todas as regiões, muito embora o seu consumo seja de aproximadamente $95.073 \mathrm{t}$, das quais em torno de $20.000 \mathrm{t}$ corresponde a grãos importados (FREITAS et al., 2013; CARVALHO et al., 2013). Entretanto, o mercado brasileiro possui um grande potencial a ser explorado, especialmente porque é uma cultura com retorno econômico mais elevado do que o milho comum, usado principalmente, sob diferentes formas na alimentação de adultos e crianças, cujo mercado consumidor abrange inúmeros países (RODOVALHO et al., 2008).

A aplicação de fertilizantes orgânicos no solo, além da disponibilização dos nutrientes necessários às plantas, está associada à melhoria das propriedades físicas do solo, como agregação, porosidade e densidade do solo, retenção e disponibilidade de água às plantas e estabelecimento de microorganismos benéficos (GIACOMINI; AITA, 2008). Além de que os preços dos adubos minerais terminam por inviabilizar o seu uso na pequena propriedade, fato que pode ser contornado com aplicação de esterco bovino que na agricultura familiar pode ser conseguido localmente. Nesse contexto, como $95 \%$ do nitrogênio encontra-se na forma orgânica, a adição de adubo orgânico pode suprir essa necessidade a custo relativamente baixo.

Mesmo assim, para um melhor desenvolvimento, crescimento $\mathrm{e}$, consequentemente, rendimento produtivo, o efeito interativo da adubação com espaçamento torna-se imprescindível para a cultura. A produtividade de grãos aumenta com o aumento da população de plantas, até atingir um nível ideal determinado pelo genótipo da planta e pelas condições ambientais. Por outro lado, a diminuição do espaçamento ocasiona redução no diâmetro do colmo, assim como aumento no número de plantas acamadas, redução na altura de plantas e na inserção da espiga, quando esse número encontra-se fora do ideal (VALENTINUZ; TOLLENAAR, 2004).

Entretanto, para obter um número de plantas que melhore a eficiência do aproveitamento de água e nutrientes, reduzindo a competição inter e intra-específica por esses fatores, é necessário considerar algumas características, entre elas, a cultivar, fertilidade e umidade do solo, além do nível de tecnologia empregado pelo agricultor (SANGOI et al., 2009). Argenta et al. (2001), ao investigarem o efeito da redução do espaçamento entre linhas sobre a produtividade de grãos de milho, concluíram que essa resposta é influenciada pelo híbrido e pela densidade de plantio na exploração.

Devido à baixa disponibilidade de informações técnicas específicas para o milho pipoca, os produtores tendem a utilizar práticas culturais recomendadas para o milho comum, as quais nem sempre são apropriadas para o milho pipoca, uma vez que exigências nutricionais e arquitetura de planta são completamente diferentes das cultivares modernas de milho comum (LEONELLO; CAZETTA; FORNASIERI FILHO, 2009).

Neste contexto, considerando a carência de informações, bem como a possibilidade de benefícios econômicos aos agricultores familiares, o presente trabalho foi utilizado com o objetivo de obter um nível de adubação orgânica conciliado a uma densidade de plantio que proporcione um melhor desenvolvimento e produção do milho pipoca.

\section{Material e Métodos}

A pesquisa foi conduzida em campo sob a forma de agricultura de sequeiro, na estação experimental da Empresa Estadual de Pesquisa Agropecuária da Paraíba (EMEPA - PB), localizada no município de Alagoinha - PB, microrregião de Guarabira, cujo clima, de acordo com a classificação de Köppen, é do tipo As', que se caracteriza por ser quente e úmido com chuvas de outono - inverno, com precipitação pluvial média anual de $1.100 \mathrm{~mm}$, em solo classificado como Luvissolo Crômico Pálico abrúptico, relevo suave ondulado (EMPRESA..., 2006), cujas características químicas e físicas apresentam-se nas Tabelas 1 e 2 e quantidade de precipitação pluvial no período de condução do experimento, na Figura 1.

A área experimental foi constituída por três blocos, com dimensões de $60,00 \mathrm{~m} \times 5,00 \mathrm{~m}$ (área total de $900 \mathrm{~m}^{2}$ ), onde se utilizou o delineamento experimental em blocos casualizados, no esquema fatorial $2 \times 5$, com três repetições. As parcelas com 5,00 m de comprimento e 5,00 m de largura, com cinco linhas de plantas, espaçadas entre si em 1,00 m, com área útil de $12,00 \mathrm{~m}^{2}$ e com seis linhas de plantas, espaçadas entre si em $0,80 \mathrm{~m}$, com área útil de $12,8 \mathrm{~m}^{2}$. Assim, foram testados dois espaçamentos: (1) - 1,00 $\mathrm{m} \times 0,20 \mathrm{~m}$ com densidade de plantio de 50.000 plantas ha ${ }^{-1} \mathrm{e}(2)-0,80 \mathrm{~m} \times 0,20 \mathrm{~m}$ com densidade de plantio de 62.500 plantas ha ${ }^{-1}$, em cinco quantidades de adubo orgânico $\left(0,5,10,15\right.$ e $20 \mathrm{t} \mathrm{ha}^{-1}$ de esterco bovino), conforme especificação na Tabela 3.

A adubação orgânica foi distribuída superficialmente sobre as parcelas, obedecendo às quantidades indicadas em cada tratamento, antes do plantio da cultura. O desbaste ocorreu aos 23 dias após a emergência das plântulas (DAE), deixando-se uma planta por cova. O controle das plantas daninhas durante o ciclo da cultura foi procedido por capina manual com a utilização de enxada, sendo a primeira aos $15 \mathrm{DAE}$. A cultivar de milho pipoca utilizada, foi a CMS 42, obtida da Embrapa Milho e Sorgo.

Durante o ciclo da cultura, em campo, foram procedidas as avaliações de altura de plantas (AP) e diâmetro do colmo (DC), semanalmente até sua estabilização e, após a colheita, a produtividade de grãos (PG) e o índice de capacidade de expansão do endosperma (ICE) dos grãos do milho pipoca. Para o ICE, utilizou-se o volume de $30 \mathrm{ml}$ de grãos e uma proveta de $1000 \mathrm{ml}$, dividindo o volume de pipoca estourada pelo volume de grãos utilizados (PACHECO; CASTOLDI; ALVARENGA, 1996).

Os dados obtidos foram submetidos à análise de variância, sendo a influência do fator Adubação testado pela regressão polinomial e a influência do fator Espaçamento pelo teste F a 5\%, empregando-se o software SAS/STAT versão 9.3 (STATISTICAL..., 2011).

Tabela 1. Caracterização química da camada superficial do solo da área experimental na profundidade de $0-20 \mathrm{~cm}$.

\begin{tabular}{|c|c|c|c|c|c|c|c|}
\hline pH & $\mathbf{A l} \mathbf{l}^{+3}$ & $\mathrm{Ca}^{+2}$ & $\mathrm{Mg}^{+2}$ & $\mathbf{N a}^{+}$ & $\mathbf{K}^{+}$ & $\mathbf{P}$ & M.O \\
\hline & \multicolumn{4}{|c|}{ - } & \multicolumn{2}{|c|}{--- $\mathrm{mg} \mathrm{dm}^{-3}$} & $\mathrm{~g} \mathrm{dm}^{-3}$ \\
\hline 5,49 & 0,025 & 2,27 & 1,18 & 0,041 & 65,18 & 5,08 & 11,37 \\
\hline
\end{tabular}


Tabela 2. Caracterização física da camada superficial do solo da área experimental na profundidade de $0-20 \mathrm{~cm}$.

\begin{tabular}{|c|c|c|c|c|c|c|c|c|}
\hline \multicolumn{3}{|c|}{ Granulometria } & \multirow{2}{*}{$\begin{array}{c}\text { Classe } \\
\text { textural }\end{array}$} & \multirow{2}{*}{ DS $^{1}$} & \multirow{2}{*}{$\mathbf{D P}^{2}$} & \multirow{2}{*}{$\mathbf{P T}^{3}$} & \multirow{2}{*}{$\frac{\mathrm{CC}^{4}}{-0,033 \mathrm{MPa}}$} & \multirow{2}{*}{$\begin{array}{c}\mathrm{PMP}^{5} \\
-1,5 \mathrm{MPa}\end{array}$} \\
\hline Areia & Silte & Argila & & & & & & \\
\hline \multicolumn{3}{|c|}{ - } & & \multicolumn{2}{|c|}{ - } & $\mathbf{m}^{3} \mathbf{m}^{-3}$ & \multicolumn{2}{|c|}{ 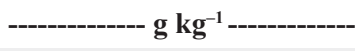 } \\
\hline 553 & 290 & 157 & $\begin{array}{c}\text { Franco } \\
\text { Arenosa }\end{array}$ & 1,39 & 2,62 & 0,47 & 228 & 49 \\
\hline
\end{tabular}

${ }^{1}$ densidade do solo (DS). ${ }^{2}$ densidade de partículas (DP). ${ }^{3}$ porosidade total (PT). ${ }^{4}$ capacidade de campo (CC). ${ }^{5}$ ponto de murcha permanente (PMP).

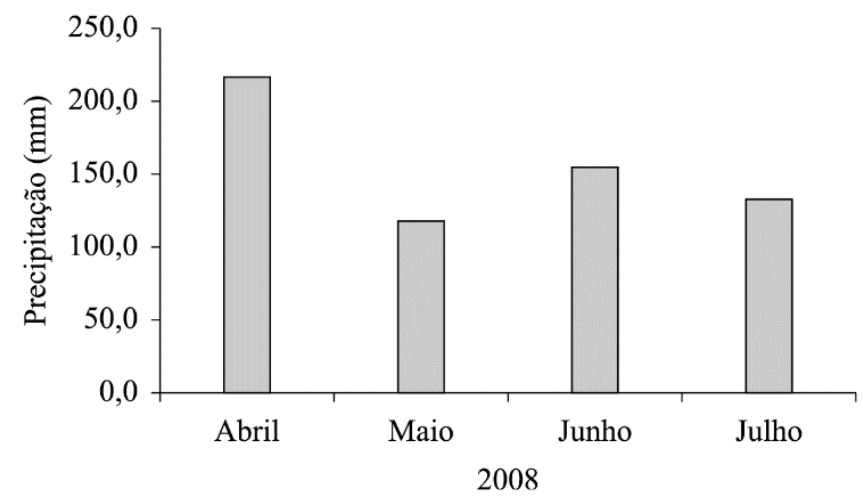

Figura 1. Precipitação pluvial durante o período do experimento na estação experimental da Empresa Estadual de Pesquisa Agropecuária da Paraíba (EMEPA-PB), Alagoinha-PB.

Tabela 3. Caracterização dos tratamentos, representando o esquema fatorial $2 \times 5$.

\begin{tabular}{|c|c|c|}
\hline Tratamentos & Espaçamento & Adubação \\
\hline $\mathbf{T}_{1}$ & $1,00 \mathrm{~m} \times 0,20 \mathrm{~m}$ & Sem adubação orgânica \\
\hline $\mathbf{T}_{2}$ & $1,00 \mathrm{~m} \times 0,20 \mathrm{~m}$ & 5,0 t de esterco bovino \\
\hline $\mathbf{T}_{3}$ & $1,00 \mathrm{~m} \times 0,20 \mathrm{~m}$ & 10,0 t de esterco bovino \\
\hline $\mathbf{T}_{4}$ & $1,00 \mathrm{~m} \times 0,20 \mathrm{~m}$ & 15,0 t de esterco bovino \\
\hline $\mathbf{T}_{5}$ & $1,00 \mathrm{~m} \times 0,20 \mathrm{~m}$ & 20,0 t de esterco bovino \\
\hline $\mathbf{T}_{6}$ & $0,80 \mathrm{~m} \times 0,20 \mathrm{~m}$ & Sem adubação orgânica \\
\hline $\mathbf{T}_{7}$ & $0,80 \mathrm{~m} \times 0,20 \mathrm{~m}$ & 5,0 t de esterco bovino \\
\hline $\mathbf{T}_{8}$ & $0,80 \mathrm{~m} \times 0,20 \mathrm{~m}$ & 10,0 t de esterco bovino \\
\hline $\mathbf{T}_{9}$ & $0,80 \mathrm{~m} \times 0,20 \mathrm{~m}$ & 15,0 t de esterco bovino \\
\hline $\mathbf{T}_{10}$ & $0,80 \mathrm{~m} \times 0,20 \mathrm{~m}$ & 20,0 t de esterco bovino \\
\hline
\end{tabular}

\section{Resultado e Discussão}

Os resultados da análise de variância estão apresentados na Tabela 4 , na qual se observou que apenas a variável produtividade de grãos a interação entre os fatores Adubação $\times$ Espaçamento foi significativa. Nas demais variáveis avaliadas apenas o fator adubação influenciou significativamente nos resultados (Tabela 4).

Para o milho pipoca, a adubação orgânica à medida que aumentou as doses, ocorreram aumentos na AP, na qual a maior dose $\left(20 \mathrm{tha}^{-1}\right)$ proporcionou maior desenvolvimento das plantas $129,5 \mathrm{~cm}$ (Figura 2) e bem expressiva quando comparado ao tratamento sem adubação $(106 \mathrm{~cm})$. Esse incremento na AP mostra o efeito direto e indireto que a adubação orgânica oferece ao solo, principalmente à sua fertilidade, uma vez que a matéria orgânica é fonte de nutrientes, principalmente de N, P, $\mathrm{S}$, além dos benefícios físicos, como o aumento da capacidade de retenção de água e de aeração (ALVES et al., 2000). Gomes et al. (2005) obtiveram resposta semelhante, avaliando milho comum, atingindo uma altura média de 2,27 cm com doses a partir de $20 \mathrm{t} \mathrm{ha}^{-1}$. Por sua vez o espaçamento não mostrou diferença significativa.

Houve aumento no desenvolvimento do colmo para doses na adubação orgânica, variando (16,8 mm a $17,2 \mathrm{~mm})$, quando comparado aquele do tratamento sem adubação $(14,0 \mathrm{~mm})$. Porém, quando comparados os tratamentos com diferentes quantidades de esterco bovino aplicados, estes não diferiram estatisticamente (Figura 3), observando-se que o aumento do $\mathrm{DC}$ pode estar associado à morfologia da planta. Segundo a Embrapa Milho e Sorgo, o DC aumenta com a fertilização das plantas. Sousa et al. (2012), mostraram que melhores valores para DC foram obtidos com o incremento do uso de biofertilizante bovino, concluindo que o uso desta fonte orgânica apresentou um aspecto nutricional positivo para esta variável nas plantas de milho comum. Da mesma forma, o espaçamento não influenciou essa variável na cultura do milho pipoca.

Com dito anteriormente, a PG do milho pipoca foi influenciada pela interação dos fatores Adubação $\times$ Espaçamento (Figura 4). À medida que aumentou a quantidade de esterco aplicado ao solo, ocorreram incrementos na variável em questão. A melhor quantidade de adubo orgânico, foi de $18,31 \mathrm{t} \mathrm{ha}^{-1}$, atingindo o ponto de máxima produção de milho de $2.952 \mathrm{~kg} \mathrm{ha}^{-1}$, no espaçamento $2(0,80 \mathrm{~m} \times 0,20 \mathrm{~m})$, comparando-se ao espaçamento $1(1,00 \mathrm{~m} \times 0,20 \mathrm{~m})$ utilizando a maior dose de $20 \mathrm{t} \mathrm{ha}^{-1}$ obteve produção de apenas $2.394 \mathrm{~kg} \mathrm{ha}^{-1}$ (Figura 4). Isso ocorreu, provavelmente, pelo espaçamento 2 apresentar um número maior de plantas por área, dada a configuração utilizada no plantio.

O aumento da densidade populacional na cultura do milho pipoca é um dos fatores que pode contribuir para a correta exploração do ambiente e do genótipo com consequências na maior PG. Entretanto, a baixa densidade de plantas reduz a competição intraespecífica, principalmente, por água e nutrientes na área, favorecendo a produção de grãos por planta, porém limitando a PG por área (VON PINHO et al., 2008). Com o aumento da população de plantas ocorre redução no tamanho das espigas, diminuindo também seu índice por planta, entretanto, a compensação na produção aconteceu pelo aumento do número de plantas por área.

O nitrogênio segundo Marschner (1995) promove funções essenciais, como a absorção de nutrientes, sendo também um componente essencial da clorofila, proteínas e hormônio de 
crescimento. Além disso, a matéria orgânica contribui com a atividade biológica do solo, fundamental para o melhor aproveitamento dos nutrientes.

Para o ICE houve influencia da adubação, entre as quantidades de adubo orgânico aplicadas, independentemente do espaçamento utilizado, para 5 e 10 tha $^{-1}$ de adubo orgânico, o ICE foi igual a 15, ou seja, o aumento de volume da flor de pipoca foi 15 vezes maior do que o volume de $30 \mathrm{ml}$ de grãos. Para os níveis de 15 e $20 \mathrm{t} \mathrm{ha}^{-1}$ de adubo orgânico, os ICEs foram 17 e 18, respectivamente, enquanto o tratamento sem adubação apresentou ICE igual a 9 (Figura 5).
No cultivo de milho pipoca algumas práticas culturais podem interferir na qualidade da pipoca, em sua capacidade de expansão, dado que essa variável tem grande importância, pois quanto maior o ICE, maior será o valor comercial, devido à melhor textura e maciez da pipoca (MOTERLE et al., 2012). Estes resultados foram semelhantes aos relatados por Pacheco, Castoldi e Alvarenga (1996), que obtiveram um valor médio de ICE de 15,38. Adicionalmente, os valores também foram semelhantes aos encontrados por Nunes et al. (2002), que observaram ICE médio de 17,5.

Tabela 4. Resumo das análises de variância pelo quadrado médio, referentes à altura de planta - AP, diâmetro de colmo - DC, produtividade de grãos - PG e índice de capacidade expansão do endosperma - ICE.

\begin{tabular}{|c|c|c|c|c|c|}
\hline Fonte de Variação & GL & $\mathbf{A P}$ & DC & PG & ICE \\
\hline Bloco & 2 & $4,98 \mathrm{~ns}$ & $2,22 \mathrm{~ns}$ & 141411.32ns & $2,10 \mathrm{~ns}$ \\
\hline Adubação (A) & 4 & $518,72 * *$ & $9,24 * *$ & $2667309.66 * *$ & $68,11 * *$ \\
\hline Espaçamento (E) & 1 & $35,51 \mathrm{~ns}$ & $0,54 \mathrm{~ns}$ & $1700129.30 * *$ & $0,30 n s$ \\
\hline $\mathbf{A} \times \mathbf{E}$ & 4 & $5,86 \mathrm{~ns}$ & $0,03 n s$ & 216154.04* & $0,71 \mathrm{~ns}$ \\
\hline Resíduo & 18 & 30,35 & 0,98 & 69907.34 & 1,69 \\
\hline Total & 29 & - & - & - & - \\
\hline CV (\%) & & 14,52 & 6,03 & 13,14 & 8,85 \\
\hline
\end{tabular}

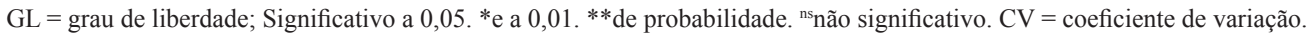

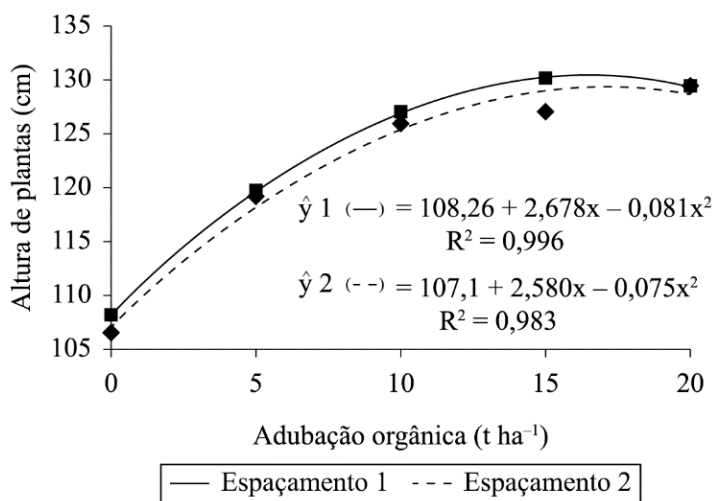

Figura 2. Altura de plantas em função de diferentes doses de adubação orgânica. Espaçamento (1) 1,00 m × 0,20 m; Espaçamento (2) 0,80 m ×0,20 m.

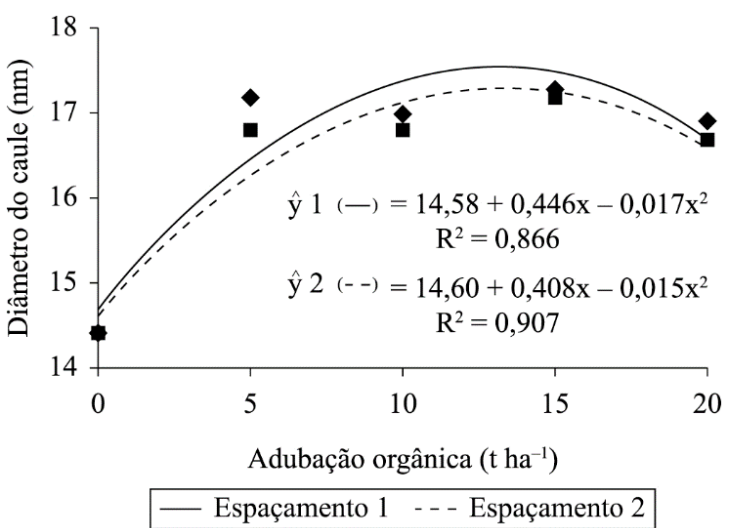

Figura 3. Diâmetro do caule das plantas em função de diferentes doses de adubação orgânica. Espaçamento (1) 1,00 m × 0,20 m; Espaçamento (2) $0,80 \mathrm{~m} \times 0,20 \mathrm{~m}$.

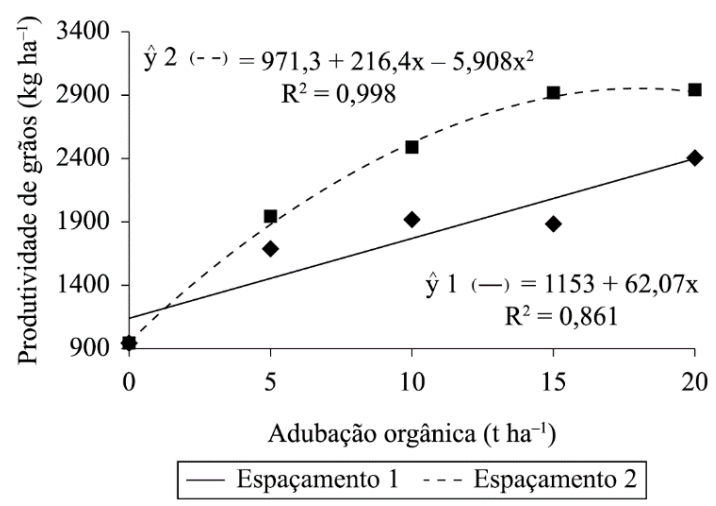

Figura 4. Produtividade de grãos de milho pipoca em função de diferentes doses de adubação orgânica e espaçamentos. Espaçamento (1) 1,00 m × 0,20 m; Espaçamento (2) $0,80 \mathrm{~m} \times 0,20 \mathrm{~m}$.

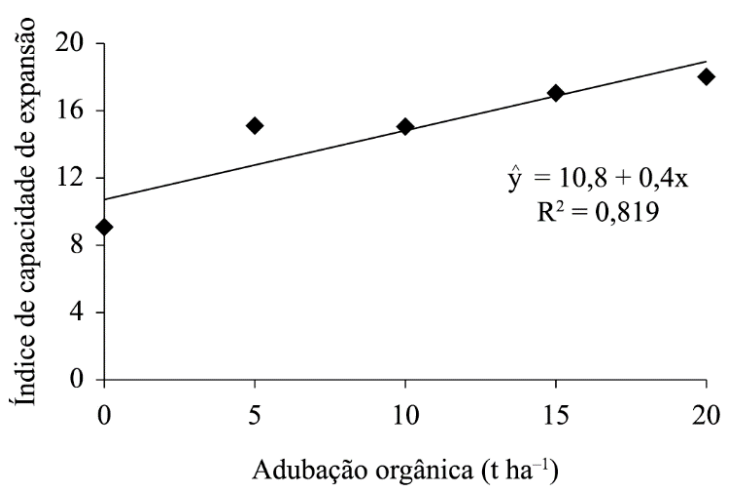

Figura 5. Índice de capacidade de expansão do endosperma de grãos de milho pipoca em função de diferentes doses de adubação orgânica. 
Rossato Júnior et al. (2013) avaliando ICE de três cultivares de milho pipoca sob diferentes espaçamentos, relatam que as cultivares não foram afetadas por nenhum arranjo espacial testado, fato também observado nessa pesquisa.

A capacidade de expansão observada para os diferentes tratamentos, com destaque para as maiores doses de adubação orgânica, pode estar associada ao fornecimento em maior quantidade de nutriente. Segundo Marschner (1995) o fósforo é responsável pela qualidade da semente sendo também importante para a formação da mesma.

\section{Conclusão}

A altura de plantas de milho pipoca aumenta com o aumento quantidades de esterco bovino aplicado ao solo;

Para o diâmetro do colmo 5,0 $\mathrm{t} \mathrm{ha}^{-1}$ de esterco bovino mostrou-se mais eficiente em relação aos demais tratamentos, por proporcionar maior valor;

A produtividade de grãos de milho pipoca é afetada pelo espaçamento e adubação orgânica, sendo que no espaçamento $0,80 \mathrm{~m} \times 0,20 \mathrm{~m}$, conciliado com 18,31 $\mathrm{t} \mathrm{ha}^{-1}$ de adubação orgânica, apresentou valor de $2.952 \mathrm{~kg} \mathrm{ha}^{-1}$;

A maior capacidade de expansão do milho pipoca foi obtida com a aplicação de adubação orgânica, sendo esta variável não influenciada pelos espaçamentos utilizados.

\section{Referências}

ALVES, E. U. et al. Produção de sementes de feijão-vagem em função de fontes e doses de matéria orgânica. Horticultura Brasileira, Brasília, v. 18, n. 3, p. 215-221, 2000.

ARGENTA, G. et al. Resposta de híbridos simples de milho à redução do espaçamento entre linhas. Pesquisa Agropecuaria Brasileira, Brasília, v. 36, n. 1, p. 71-78, 2001. http://dx.doi.org/10.1590/ S0100-204X2001000100009.

CARVALHO, C. et al. Anuário brasileiro do milho 2013. Santa Cruz do Sul: Gazeta Santa Cruz, 2013. 128 p.

EMPRESA BRASILEIRA DE PESQUISA AGROPECUÁRIA - EMBRAPA. Centro Nacional de Pesquisa de Solos. Sistema Brasileiro de Classificação de Solos. Rio de Janeiro: Embrapa SPI, 2006. 306 p.

FREITAS, I. L. J. et al. Ganho genético avaliado com índices de seleção e com REML/Blup em milhopipoca. Agropecuária Brasileira, Brasília, v. 48, n. 11,p. 1464-1471, 2013. http://dx.doi.org/10.1590/ S0100-204X2013001100007.

GIACOMINI, S. J.; AITA, C. Cama sobreposta e dejetos líquidos de suínos como fonte de nitrogênio ao milho. Revista Brasileira de Ciência do Solo, Viçosa, v. 32, n. 1, p. 195-205, 2008. http:// dx.doi.org/10.1590/S0100-06832008000100019.

GOMES, J. A. et al. Adubações orgânica e mineral, produtividade do milho e características físicas e químicas de um Argissolo Vermelho-Amarelo. Acta Scientiarum Agronomy, Maringá, v. 27, n. 3, p. 521-529, 2005. http://dx.doi.org/10.4025/actasciagron. v27i3.1472.

LEONELLO, L. A. F.; CAZETTA, D. A.; FORNASIERI FILHO, D. Características agronômicas e qualidade comercial de cultivares de milho pipoca em alta população milho pipoca em alta população. Acta Scientiarum Agronomy, Maringá, v. 31, n. 2, p. 215-220, 2009.

MARSCHNER, H. Mineral nutrition of higher plants. London: Academic Press, 1995. 889 p.

MOTERLE, L. M. et al. Combining ability of popcorn lines for seed quality and agronomic traits. Euphytica, Wageningen, v. 185, n. 3, p. 337-347, 2012. http://dx.doi.org/10.1007/s10681-011-0458-2.

NUNES, H. V. et al. Adaptabilidade e estabilidade de cultivares de milhopipoca por meio de dois métodos de classificação. Revista Brasileira de Milho e Sorgo, Sete Lagoas, v. 1, n. 3, p. 78-88, 2002.

PACHECO, C. A. P.; CASTOLDI, F. L.; ALVARENGA, E. M. Efeito do dano mecânico na qualidade fisiológica e na capacidade de expansão de sementes de milho pipoca. Revista Brasileira de Sementes, Brasília, v. 18, n. 2, p. 267-270, 1996. http://dx.doi. org/10.17801/0101-3122/rbs.v18n2p267-270.

RODOVALHO, M. et al. Survival heritability in 169 families of white grain popcorn: a Bayesian approach. Ciencia e Investigación Agraria, Santiago, v. 35, n. 3, p. 303-309, 2008.

ROSSATO JÚNIOR, J. A. D. S. R. et al. Popping expansion and yield responses of popcorn cultivars under different row spacings and plant populations. Pesquisa Agropecuaria Brasileira, Brasília, v. 48 , n. 12 , p. $1538-1545$, 2013. http://dx.doi.org/10.1590/ S0100-204X2013001200002.

SANGOI, L. et al. Uniformidade no desenvolvimento e resposta de cultivares de milho ao incremento na população de plantas. Revista Brasileira de Milho e Sorgo, Sete Lagoas, v. 8, n. 1, p. 69-81, 2009.

SOUSA, G. D. et al. Crescimento inicial do milho sob diferentes concentrações de biofertilizante bovino irrigado com águas salinas. Revista Ciência Agronômica, Fortaleza, v. 43, n. 2, p. 237-245, 2012. http://dx.doi.org/10.1590/S1806-66902012000200005.

STATISTICAL ANALYSIS SYSTEM - SAS. SAS/STAT 9.3 User's Guide. Cary, NC: SAS Institute Inc, 2011. 8621 p.

VALENTINUZ, O. R.; TOLLENAAR, M. Vertical profile of leaf senescence during the grain filling period in older and newer maize hybrids. Crop Science, Madison, v. 44, n. 3, p. 827-834, 2004. http://dx.doi.org/10.2135/cropsci2004.0827.

VON PINHO, R. G. et al. Adubação nitrogenada, densidade e espaçamento de híbridos de milho em sistema plantio direto na região sudeste do Tocantins. Bragantia, Campinas, v. 67, n. 3, p. 733-739, 2008. http://dx.doi.org/10.1590/S0006-87052008000300023. 